Bolm Inst, oceanogr., S. Paulo, 35(1):1-5, 1987

\title{
COMPORTAMENTO ASSOCIATIVO DE Fregata magnificens (FREGATIDAE, AVES) \\ E sula leucogaster (SULIDAE, AVES) NO LITORAL CENTRO-NORTE DO ESTADO DE SÃO PAULO
}

\section{Marcio Amaral REZENDE}

Fundação Parque Zoológico de São Paulo

Instituto Oceanogräfico da Universidade de São Paulo (Caixa Postal 9075, 01051 São Paulo, SP)

\begin{abstract}
The frigatebird (Fregata magnificens) often is referred to as a kleptoparasite of the brown booby (Sula leucogaster). This paper however, shows that the relationship between these species is more complex and that kleptoparasitism can be interpreted as just a part of a whole process of mutual exploration. When these birds fly behind fishing boats, F. magnificens locates the food source first and $S$. leucogaster then moves in and catches fish more efficiently in such a way that the frigatebird can no longer fish and has to fly coway. When the fishing period is over then the frigatebird is thought to approach the brown boobies in order to get fish from them, as described in the literature. This leads to a revision on the interpretation about the relation between these species, from that of kleptoparasitism to this of mutual exploration.

Descriptors: Marine birds, Feedings behaviour, Interspecific relationships, Symbiosis, Fregatidae, Sulidae, Il ha dos Alcatrazes: SP.

Descritores: Aves marinhas, Comportamento alimentar, Relações inter-especificas, Simbiose, Fregatidae, Sulidae, Il ha dos Alcatrazes: SP.
\end{abstract}

\section{Introdução}

A ocupação de āreas de uso sobrepostos, tais como território de pesca e nidificação entre fregatas (Fregata magnificens) e atobās (Sula leucogaster) è relativamente bem conhecida na literatura. De acordo com a revisão de Nels on (1983), existe um consenso no diagnóstico de que a Fregata magnificens é um cleptoparasita de Sula leucogaster. 0 objetivo deste trabalho é o de apontar evidências que mostrem que esta conclusão é precipitada e o de chamar a atenção para o aparente conflito entre estes dois fatos; como se explica que uma ave, sendo prejudicada pela outra, tolere nidificar no mesmo sítio do seu parasita e como estas espécies, sendo as fregatas parasitas dos atobás e nidificando em áreas prōximas, evoluiram de maneira tão distinta dos atobás, principalmente no que tange à niḍificação. No curso destas observações, é sugerido que esta relação inter-específica

Cont. n. 657 do Inst. oceanogr, da usp. pode na verdade ser muito mais complexa. As observações abaixo mostram que pode haver, pelo menos, um nível de exploração mútua entre as duas populaçoes, de tal forma a justificar o habito de nidificarem em locais próximos, quando isto ocorre.

Estas duas espécies possuem características de vôo e estratégia de pesca marcadamente diferentes. Os atobás são tipicamente aves mergulhadoras, capazes de uma rápida penetração no mar o que thes favorece a apreensão do alimento (Ne1son, 1971). Este tipo de vôo requer da ave características como alta carga alar, instabilidade aerodinâmica e outros fatores aerodinâmicos que, por outro lado, desfavorecem o vôo de térmica (Welch \& Irving, 1977). Estas características são opostas a aquelas encontradas nas fregatas, favorecendo, portanto, a utilização de térmicas. A capacidade de utilizar térmicas permite às aves que as possuem, 
Bolm Inst. oceanogr., S Paulo, 35(1), 1987

- ganho de grandes altitudes com pouco esforço num espaço de tempo relativamente curto. Isto é vantajoso na exploração do território de caça, pois aumenta o campo visual para uma localização mais rápida da fonte de alimento (Pennycuick, 1973). 0 preço desta capacidade porém pode ser alto, uma vez que a baixa carga alar e vôo estável como nas fregatas resulta numa inabilidade de mergulhar, tendo a ave que limitar a apreensão de espécies a aquelas que nadem ou mesmo voem, próximo à superfície do mar, tanto que as aves da famîlia Fregatidae são especialistas na pesca de peixes voadores (Nelson, 1983). Esta oposição de características, de certa forma complementa a atividade de uma e outra, reforçando a idéia de que estas aves poderiam tirar proveito uma da outra. Neste contexto, a fregata desempenharia a função de localizar a fonte de alimento e o atobá a de capturá-1o, tornando a operação, como um todo, mais eficiente do que se desempenhada isoladamente. Se isto é verdadeiro então o que a literatura diagnóstica como cleptoparasitismo ou "pirataria" deveria ser visto como uma interessante forma de distribuição do pescado.

\section{Material e métodos}

As colonias investigadas foram as da Ilha dos Alcatrazes, investigação esta feita em duas viagens, uma em outubro e, a seguinte, em novembro de 1986.

A qualidade do alimento foi observade pelo processo de coleta de material regurgitado espontaneamente por filhotes e filhotões de fregatas na Ilha de Alcatrazes. Utilizou-se uma balança de pratos com sensibilidade para $0,1 \mathrm{gr}$ para pesar as amostras.

A fim de dimensionar a colônia de fregatas, foi feito a contagem de ninhos por copas, uma vez que estas aves nidificam sobre arbustos e árvores em ilhas afastadas do continente (Ne1son, 1983). Estes foram divididos em dois grupos, arbustivo e arbóreo, cujas característica é dada pelo padrão de verde das copas, respectivamente claros e escuros. Contou-se os ninhos em cada copa por categoria num número significante, tendo como referência o nível de confiança de $95 \%$ (Snedecor \&
Cochran, 1980). O total foi avaliado percorrendo a ilha com binóculo e contando-se o número de copas arbustivas e arbóreas e multiplicando as respectivas médias por cada valor.

A colônia de Sula leucogaster não foi avaliada devido a falta de um método satisfatório para estimá-la diretamente ou estatisticamente. Os ninhos destas aves na ilha são de difícil acesso, muitos deles sob o manto vegeta1, o que torna impossível uma contagem a maior distância.

0 arrastão para o estudo de avaliar a aproximação das aves, foi feito com uma embarcação típica para a atividade, pertencente ao Instituto Oceanogräfico ("Veliger II") entre a costa, ao largo da Ilha de Santo Amaro e à cota de 15 metros, medida pelo eco-sonda de bordo.

\section{Discussão e resultados}

Ao longo de duas viagens à Ilha de Alcatrazes, observou-se uma grande colonia de Fregata magnificens instalada lado a 1 ado, com alguma sobreposição, a outra colônia de Sula leucogaster. A análise de material regurgitado pelas aves, coletado na segunda viagem a ilha, mostrou que mais de $90 \%$ das espécies de peixes eram espécies demersais (Tab. 1). Devido a não-adaptação das fregatas para mergulhar no mar, o conteúdo alimentar indica que a mesma não poderia ter obtido o alimento por meios próprios. A sugestão natural fornecida pela literatura dirige as suspeitas para os atobás (S. leucogaster), tipicamente mergulhadores. Todavia não se acredita que os atobäs possam, embora aves mergulhadoras, penetrar muito profundamente no mar (Ashmole \& Ashmole, 1968). Portanto, os atobás também estariam descartados como alternativa para justificar a pesca dos peixes demersais encontrados no material regurgitado. Para se ter uma idéia de grandeza, cita-se como exemplo o caso de Paralonchurus brasiliensis (Maria-Luíza), a espécie mais freqüente encontrada no material analisado. Esta espécie é muito pouco freqüente ou mesmo ausente em profundidades menores que $10 \mathrm{~m}$ (Menezes \& Figueiredo, 1980). Estes peixes são comuns nos arrastões realizados perto da costa, como por exemplo, ao largo da Ilha de Santo Amaro, a poucos qui- 
Tabela 1, Lista de espécies de peixes regurgitados por filhotes e filhotões de Fregata magnificens da I lha dos Alcatrazes (total coletado $1680 \mathrm{gr}$ em 11 coletas pesando em média $157 \mathrm{gr}$ var $=419$, erro $16 \mathrm{gr}$, $n=11,35 \%$ ident $i$ icados)

\begin{tabular}{llcc}
\hline Espécie & Ocorräncle & $\begin{array}{c}\text { compr. } \\
\text { (cm) }\end{array}$ & $\begin{array}{c}\text { Percentagem } \\
\text { (poso) }\end{array}$ \\
\hline Pellona harroweni & peläglco & 12,7 & 7,9 \\
Ponichthys porosissinus & demersal & 17,0 & 3,7 \\
Cynoscion jamaicensis & demersal & 12,0 & 32,0 \\
Orthopristis ruber & demersal & 15,5 & 8,1 \\
Paralonchurus brasiliensis & demersal & 18,3 & 44,7 \\
Stelliber nastriber & demersal & 8,5 & 3,5 \\
\hline
\end{tabular}

lômetros do Guarujā o que sugere que as fregatas poderiam estar obtendo o pescado de pescadores costeiros daquela região. Esta possibilidade é reforçada pelo fato de a colônia ter crescido, pelo menos durante a ültima metade do século, Luederwaldt \& Fonseca (1922) contaram o número de ninhos na Ilha dos Alcatrazes a mais de 60 anos atrás. Eles registraram um total de 450 ninhos de $F$. minor (esta identificação não é confirmada pela nossa viagem e, também, pelo fato, de hoje, sabermos que esta espécie nidifica apenas em ilhas e atóis oceânicos (Nelson, 1967; Diamond, 1972), e por ser $F$. magnificens a espécie típica de ilhas costeiras) ao paso que a nossa contagem, feita em novembro de 1986, revelou um total de 1500 ninhos de Fregata magnificens (Tab, 2). Ao que tudo indica, a pesca por arrastão era certamente menos extensiva a 20 anos atrás do que nos dias de hoje. Se confirmado que existe uma relação entre o uso de arrastão e o tamanho da colônia de fregatas na ilha, ficarä demonstrado a importância desta atividade humana no tamanho da colônia. Analisou-se esta possibilidade fazendo um arrastão de pesca. Ambas espécies, o atobá e a fregata, acompanharam o barco a partir do momento que se iniciou a triagem de peixes. Observou-se que existe uma ordem consistente na aproximação das aves ao barco após a retirada da rede e início da triagem (Fig. 1). As fregatas sempre chegaram antes e recolhiam da superfície os peixes descartados, com facilidade, pelo método de pesca em vôo (Nelson, 1983). Algum tempo depois, cerca de 5 a $10 \mathrm{~min}$, chegavam os atobás (Sula leucogaster). A maior capacidade de manobras dos atobás sobre a das fregatas foi patente e, em poucos minutos, suplantaram as fregatas com nítida facilidade, de tal forma que, após algum tempo as fregatas não conseguiram mais apanhar peixes da superfície, chegando sempre mais atrasadas que os atobás. As fregatas, depois de um número de tentativas inúteis, abandonaram o encalço da embarcação ganhando

Tabela 2. Contagem de ninhos com filhotes ou filhotões, mas não ninhos com adultos, incubando ou fazendo "display" de corte

\begin{tabular}{lcc}
\hline & Arbustos & Arvores \\
\hline Nümero de ninhos & 6,62 & 14,1 \\
Amostragem & 50 & 8 \\
Erro padräo & 3,1 & 3,9 \\
Total de copas & 98 & 71 \\
Total de ninhos & 648 & 1001 \\
\hline
\end{tabular}

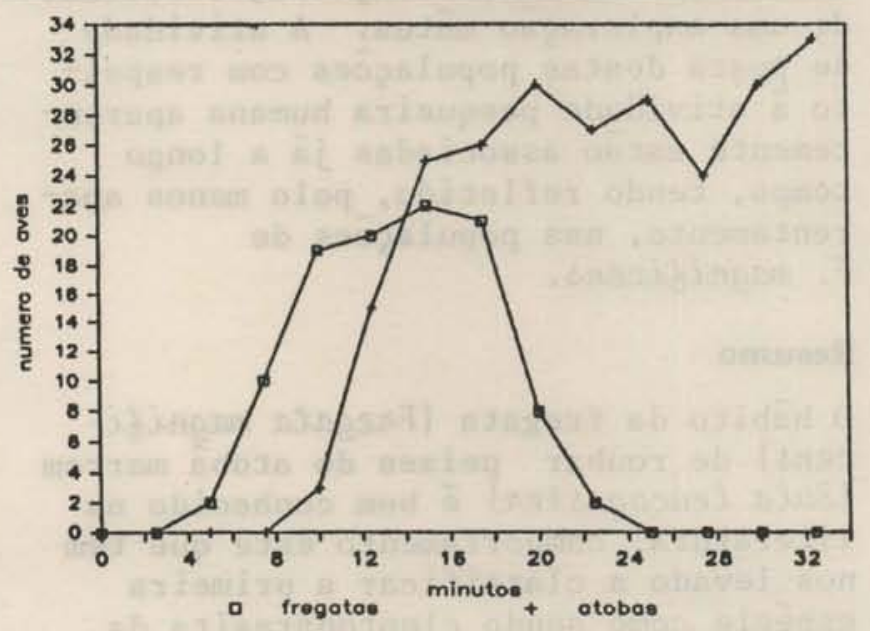

Fig. 1, Nümero de aves por espécie agrupadas durante o processo de triagem de peixes no convës apōs pesca, por arrastão. As contagens foram feitas visualmente num intervalo de 2,5 minutos por trinta minutos. 
altura em térmicas e desaparecendo, provavelmente na procura de uma outra embarcação. Este comportamento foi idêntico em todos os lançamentos do dia (totalizando em 3 ). Se este comportamento for significante, então, a afirmativa de que o atobá é cleptoparasita da fregata está invertida com respeito à pesca oportunista (ou mais propriamente, coleta de peixe) feita no rastreio de barcos pesqueiros.

\section{Conclusões}

A hipōtese levantada é que existe uma divisão de atividades entre as duas populações de aves. Aparentemente, as populações de fregata são eficientes em localizar os barcos pesqueiros e, em identificar se dos mesmos existem peixes sendo descartados. Esta colocação se jusfica devido à habilidade das fregatas de subir térmicas com facilidade em oposição ao vôo mais pesado dos atobás, De acordo com o exposto e o já previamente observado, os atobás se juntam ao bando de fregatas após a 1ocalização do barco pesqueiro por agregação, a lembrança da estratégia na localização de térmicas observado em aves terrestres (Accipitridae, Pennycuick, 1972). O comportamento cleptoparasitário da fregata sobre o atobá poderia então ser visto por uma divisão do fruto de uma atividade conjunta, resultado de uma exploração mútua. A atividade de pesca destas populações com respeito à atividade pesqueira humana aparentemente estão associadas jầ a longo tempo, tendo refletido, pelo menos aparentemente, nas populaçoes de

F. magnificens.

\section{Resumo}

0 hábito da fregata (Fregata magnificens) de roubar peixes do atoba marrom (Sula leucogaster) é bem conhecido na literatura, comportamento este que tem nos levado a classificar a primeira espécie como sendo cleptoparasita da segunda. Este trabalho, no entanto, mostra que a relação entre estas duas espécies é mais complexa e que o comportamento cleptoparasitário pode ser interpretado como sendo apenas parte de todo um processo de exploração mútua. Quando estas aves voam no encalço de embarcações pesqueiras, as fregatas localizam a fonte de alimen- to, sendo entäo seguidas pelos atobás que aparecem logo após, apanhando os peixes mortos com muito mais eficiência, de tal maneira que as fregatas não conseguem mais pescar, tendo que abandonar a atividade. Quando os atobás terminam sua atividade pesqueira, ou mesmo após um número deste ciclo, sugere-se que a fregata venha a procurar os atobás, roubando-1hes parte do pescado, fenomeno este bem descrito na literatura. Esta observação conduz a uma revisão da interpretação acerca da relação entre estas espécies, até então, considerada como cleptoparasitismo para a de exploração mútua.

\section{Agradecimentos}

Agradeço a colaboração do Dr Noriyoshi Yamaguti do Instituto Oceanográfico na identificação do material regurgitado, de minha esposa, Manuela D. Hollack Leite me auxiliando na coleta de informaçoes na Ilha dos Alcatrazes, à estagiāria Marcia Karnauchovas pela colaboração prestada na coleta e levantamento bibliográfico e à tripulação do "Veliger II". Agradeço, tambèm, ao Dr Phan Van Ngan pelos valiosos comentários feitos na revisão deste manuscrito.

\section{Referências bibliográficas}

ASHMOLE, M. J. \& ASHMOLE, N. P. 1968. The use of food samples from sea birds in the study of seasonal variation in the surface fauna of tropical oceanic areas. Pacif. Sci., 22(1):1-9.

DIAMOND, A. W. 1972. Sexual dimorphism in breeding cycles and unequal sex ratio in magnificent frigate-birds, Ibis, 114(3):395-398.

LUEDERWALDT, H, \& FONSECA, J. P. da 1922. A ilha dos Alcatrazes. Revta Mus. paul., S Paulo, 13:441-512.

NELSON, J. B. 1967. Etho-ecological adaptations in the Galapagos Islands. Nature, Lond., 214:318.

1971. The biology of Abbot's booby, Sula abboti. Ibis, $113(4): 429-467$. 
NELSON, J. B. 1983. Seabirds, their biology and ecology. London, Hamlyn, 224p,

MENEZES, N, A, \& FIGUEIREDO, J, L. 1980. Manual de peixes marinhos do sudeste do Brasil. IV. Teleostei (3). São Paulo, Museu de Zoologia da Universidade de São Paulo, 96p.

PENNYCUICK, C. J. 1972. Soaring behaviour and performance of some East African birds, observed from a motor glider. Ibis, 114:178-218.
PENNYCUICK, C. J. 1973. The soaring flight of vultures. Scient. Am,, $229(6): 102-109$.

SNEDECOR, G. W. \& COCHRAN, W. G. 1980. Statistical methods. $7^{\text {th }}$ ed. Ames, Iowa, Iowa State University Press. 507p.
(Recebido em 09-12-87; ace i to em 22-04-87) 